\title{
Successful Outcome of an Elderly Patient with Small Cell Lung Cancer with only Alternative Treatments: A Case Report
}

\author{
Sanghun Lee ${ }^{1}$, Jeonghyun $\mathrm{Joo}^{2}$, Songha $\mathrm{Chon}^{3}$ \\ ${ }^{1}$ Department of Medical Consilience, Graduate school, Dankook University \\ ${ }^{2}$ Department of Korean Internal Medicine, Comprehensive and Integrative Medicine Hospital \\ ${ }^{3}$ Department of Hemato-oncology, Comprehensive and Integrative Medicine Hospital
}

Background: Small cell lung cancer (SCLC) tends to grow more rapidly and spread much faster than non-small cell lung cancer (NSCLC). A concurrent combination of chemotherapy and thoracic radiotherapy is suggested as the standard conventional treatment, but it is more challenging for elderly patients having pulmonary and cardiovascular comorbidities.

Case presentation: Here we present a case of an 80-year-old male, current smoker diagnosed with SCLC in limited stage T3N0M0 (36mm right upper lobe, satellite nodule) in Dec, 2015. The standard concurrent chemoradiotherapy was not available for his comorbidities, which included chronic obstructive pulmonary disease (COPD) and angina pectoris. Furthermore, he and his family refused the recommended chemotherapy or radiotherapy exclusively. Alternatively, he received various non-conventional treatments including local radiofrequency hyperthermia, mistletoe, and Traditional Korean medicine including acupuncture, moxibustion and herbs since Jan. 2016. Despite the progression in primary tumor size, there have been no other distant relapse so far, and the patient has been in stable condition ever since.

Conclusion: We suggest that a combination of various alternative treatments could be a candidate for elderly patients intolerable to conventional cytotoxic treatments.

Key Words : Small cell lung cancer, Elderly patients, Alternative therapy

\section{Introduction}

Lung cancer is the leading cause of cancer death worldwide, and is divided into small cell lung cancer (SCLC, 15\% of all cases) and non-small cell lung cancer (NSCLC, $85 \%$ of all cases). In the past few decades, advances in targeted chemotherapy have been helpful to treat non-small cell lung cancer (NSCLC), but not for SCLC ${ }^{1)}$. Furthermore, prognosis in SCLC is very dismal compared to NSCLC by its rapid doubling time, high grow fraction, early development of widespread metastases. Therefore, the staging system in SCLC is simply dichotomized into a limited stage (a tumor volume encompassed in one radiation portal) and extensive stage (all other disease spread) owing to aggressive early loco-regional and distant spread of

\footnotetext{
- Received:6 March 2018 - Revised : 3 May 2018 Accepted : 3 May 2018

- Correspondence to : Songha Chon

Department of Hemato-oncology, Comprehensive and Integrative Medicine Hospital, 77, Duryugongwon-ro, Nam-gu, Daegu, Republic of Korea

Tel : +82-53-670-5737, Fax : +82-53-670-6001, E-mail : chonsongha@daum.net
} 
SCLC $^{2)}$. By reason that a local treatment such as surgery is not beneficial for a limited stage, systemic chemotherapy combined with chest irradiation is strongly recommended. However, most patients die from recurrent disease in spite of the dramatic initial response to the chemotherapy and radiation ${ }^{3}$.

SCLC risk increases with the cumulative duration and intensity of smoking, and more than $90 \%$ of patients are elderly heavy current or ex-smokers with various pulmonary, cardiovascular, and metabolic comorbidities $^{4}$. Thus, elderly patients older than 70 years have inferior outcomes when compared to younger patients because they are less likely to be subjected to conventional treatments ${ }^{5}$. In cases without treatment, median survival has been reported to be 2-4 months ${ }^{6}$. In view of this dismal prognosis, there is a need to propose treatment to improve the health-related quality of life and overall survival. The following report concerns the successful outcome in an elderly heavy smoker patient with SCLC and pulmonary and cardiovascular comorbidities via non-conventional treatments.

\section{Patients and Method}

\section{Patient characteristics and medical history}

An 80-year-old Korean male patient was diagnosed with SCLC in a limited stage (T3N0M0, 36mm right upper lobe, satellite nodule) in December 2015 following presentation with a routine check-up. (Fig. 1) His medical history included tuberculosis lymphadenitis 25 years ago, which was cured after medication, and colon cancer 7 years ago, which was surgically resected. He has been diagnosed with moderate chronic obstructive pulmonary disease (COPD) and angina pectoris since 2009. His social history was significant for smoking one pack of cigarettes daily for 50 years, occasional alcohol use, and no other substance use. His European Cooperative Oncology Group (ECOG) performance status was 1, meaning restricted in physically strenuous activity, but ambulatory and able to carry out work of a light or sedentary nature, e.g., light house work, office work. The standard concurrent chemoradiotherapy was not intolerable for his comorbidities. Furthermore, he and his family refused either chemotherapy or radiotherapy exclusively after considering the clinical benefits and physiological costs of cytotoxic treatment.

\section{Treatment course}

For these reasons, the patient visited us in January 2016 to receive alternative therapy. The treatment plan included local radiofrequency hyperthermia, mistletoe, and Traditional Korean treatments such as acupuncture, moxibustion and herbs. Local radiofrequency hyperthermia was carried out using the EHY 2000 device (Oncotherm GmbH, Troisdorf, Germany). A 30-cm-diameter electrode was applied and performed for $60 \mathrm{~min}$ per session, three sessions per week, for a total of 12 sessions. The applied power was gradually and linearly increased from 60 to $140 \mathrm{~W}$, depending on the tolerance of the patient. Abnobaviscum ${ }^{\circledR} \mathrm{F}$, a standardized preparation of aqueous European mistletoe extract from the host tree Fraxinus manufactured by Abnoba GmbH, Germany was injected subcutaneously. The initial dose was $0.02 \mathrm{mg}$ three times a week, which was gradually increased 10 -fold. Thereafter, $20 \mathrm{mg}$ twice a week was administered since April 2016, and the number of times per week has been reduced to once a week since August 2016. He was administered with a herbal extract including Rhus verniciflua stokes and a decoction of Bojungikki-tang prepared from a mixture of chopped crude herbs (Astragalus membranaceus (6g), Panax ginseng C.A.Meyer (4g), Atractylodes macrocephala Koidzumi (4g) Glycyrrhiza uralensis (4g), Angelica gigas Nakai (2g), Citrus unshiu 
Markovich (2g), Cimicifuga heracleifolia (2g), Bupleurum falcatum L. (2g)). He also received acupuncture and moxibustion weekly ever since to strengthen pulmonary function.

\section{Results}

A chest CT scan (Fig. 1) in April 2016, 15 weeks after the treatment initiation, showed a stable disease of the mass noted previously in the right upper lung. Despite the progression demonstrated by the sequentially followed CT scans (Fig. 1), there was no metastasis of his cancer in the lung and abdominopelvic cavity or elsewhere. The biochemical parameters associated with liver and renal functions and the complete blood count test were within the normal range
(Table 1), and no significant adverse effects from various treatments have been observed. His overall survival is over 2 years at this time, and he is fully active and doing well without weight loss $(61 \mathrm{~kg})$.

\section{Discussion}

In the past decade, cancer research has included investigations of the tumor microenvironment and interaction with cancer cells because various surrounding cells, including immune cells play, an important role in tumorigenesis ${ }^{7)}$. However, until recently, conventional cancer treatments have been generally cytotoxic not only to tumor cells. Thus, broad damage of the cells surrounding the tumor leads to cancer progression and metastasis ${ }^{8)}$. Therefore, a

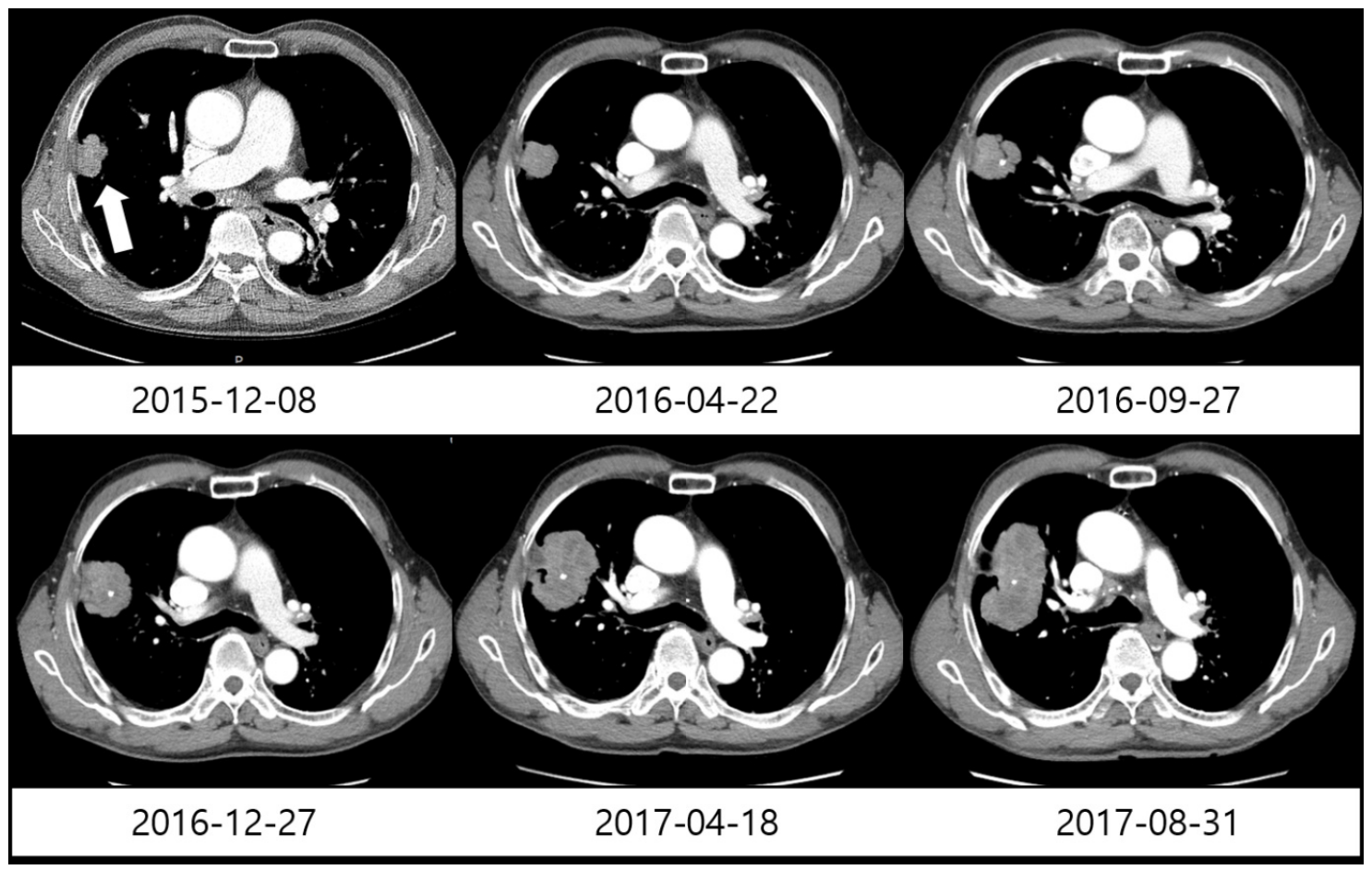

Fig. 1. A chest CT scan dated December 8, 2015 revealed an approximately $3.6 \mathrm{~cm}$ solid nodule in the upper right lobe. A follow-up chest CT scan dated April 22, 2016 showed stable disease of the mass after 15 weeks of non-conventional treatment. The sequential chest CT scans demonstrated the progression but no metastatic regions including the mediastinal lymph nodes. 
Table 1. Laboratory Examinations

\begin{tabular}{|c|c|c|c|c|}
\hline Lab results & February 2016 & April 2017 & March 2018 & References \\
\hline WBC (/uL) & 6500 & 5000 & 6300 & $4000 \sim 1000$ \\
\hline Neutrophil segment (\%) & 68.1 & 57.7 & 63.4 & $50 \sim 80$ \\
\hline Hemoglobin $(\mathrm{g} / \mathrm{dL})$ & 12.9 & 12.8 & 12.1 & $13 \sim 17$ \\
\hline Hematocrit & 37.5 & 38.2 & 37.1 & $40 \sim 54$ \\
\hline Platelet $\left(\times 10^{3} / \mathrm{uL}\right)$ & 207 & 240 & 318 & $150 \sim 500$ \\
\hline AST (IU/L) & 19 & 21 & 27 & $5 \sim 40$ \\
\hline $\operatorname{ALT}(\mathrm{IU} / \mathrm{L})$ & 17 & 15 & 19 & $5 \sim 40$ \\
\hline ALP (IU/L) & 67 & 62 & 75 & $30 \sim 120$ \\
\hline $\mathrm{LDH}(\mathrm{IU} / \mathrm{L})$ & 387 & 377 & 278 & $140 \sim 271$ \\
\hline Total Bilirubin (mg/dL) & 0.49 & 0.73 & 0.54 & $0.2 \sim 1.2$ \\
\hline Total protein $(\mathrm{g} / \mathrm{dL})$ & 7.7 & 6.3 & 6.6 & $6.5 \sim 8.3$ \\
\hline Albumin (g/dL) & 3.6 & 3.8 & 3.4 & $3.5 \sim 5.2$ \\
\hline BUN (mg/dL) & 16.6 & 11.4 & 11.9 & $8 \sim 20$ \\
\hline Creatinine $(\mathrm{mg} / \mathrm{dL})$ & 0.90 & 0.78 & 0.80 & $0.5 \sim 1.2$ \\
\hline $\mathrm{Ca}(\mathrm{mg} / \mathrm{dL})$ & 8.9 & 8.0 & 8.7 & $8 \sim 10.2$ \\
\hline $\mathrm{Mg}(\mathrm{mg} / \mathrm{dL})$ & 2.1 & 2.2 & 2.2 & $1.58 \sim 2.55$ \\
\hline $\mathrm{Na}(\mathrm{mEq} / \mathrm{L})$ & 138 & 143 & 140 & $135 \sim 148$ \\
\hline $\mathrm{K}(\mathrm{mEq} / \mathrm{L})$ & 4.5 & 4.5 & 4.3 & $3.5 \sim 5.1$ \\
\hline
\end{tabular}

novel approach to optimizing therapy for tumor microenvironments is necessary to control multiple pathways supporting the survival of cancer cells as well as the surrounding cells. Our case suggests that a combination of alternative treatments could be a candidate to control the tumor and surrounding cells, such in SCLC, the most aggressive cancer type.

Several herbs that are traditionally used in East Asia have been proven to improve tumor microenvironments by immunomodulating or anti-angiogenic effects ${ }^{9), 10)}$, Bojungikki-tang (Bu-Zhong-Yi-Qi-Tang in Chinese or Hochu-ekki-to in Japanese) was clinically reported to be beneficial for elderly people to restore age-related impairment of the immune function by enhancing the natural killer activity against tumor cells and a significant increase in the serum IFN- $\gamma$ level ${ }^{11)}$. Preclinical studies also demonstrated that it enhances immune activity including the restoration of anti-tumor T-cell response, an induction of the augmentation of natural killer activity, dendritic cell maturation, and mitogenic activity to lymphocytes ${ }^{12), 13)}$. Rhus verniciflua stokes were reported to inhibit angiogenesis by some preclinical models ${ }^{14)}$.

Local radiofrequency hyperthermia has been proposed as an acceptable adjuvant to treat SCLC ${ }^{15}$. Cancer cells are vulnerable to heat due to the disorganized and compact vascular structure compared to healthy tissues that maintain their temperature more easily. Hyperthermia is a direct cause for tumor cells to undergo apoptosis as well as produce heat shock proteins providing a tumor-selective target recognition structure for natural killer cells ${ }^{16}$. Similarly, mistletoe (Viscum album) extract is currently used as an important part of adjuvant tumor therapy ${ }^{17)}$. Three components of mistletoe, namely viscotoxins, polysaccharides, and lectins, may be responsible for stimulating the immune system and inhibiting cancer growth. In addition, treatment with Viscum album extract has caused a significant inhibition of angiogenesis in vitro and in vivo. In summary, these alternative treatments might be responsible for the anti-cancer effects in the way of ameliorating tumor microenvironments ${ }^{18)}$.

In general, elderly patients, like our case, are expected to show poor survival compared to younger patients 
due to greater comorbidities and poor performance. Despite the dismal prognosis in SCLC, our case subject has lived over 2 years after taking non-conventional treatment exclusively. Furthermore, no toxicities were observed for over 2 years. We suggest that the treatment mentioned above could be a candidate to inhibit the progression of SCLC in elderly patients even though primary therapy could not be determined. Therefore, it is necessary to investigate the synergy through various treatments in the future.

\section{Acknowledgment}

This work was supported by a grant of Comprehensive and Integrative Medicine $R \& D$ project through Comprehensive and Integrative Medicine Institute, funded by the Ministry of Health \& Welfare, Republic of Korea (Grant Number : 090-091-30003038-301-320-01)

\section{Disclosure}

The authors report no conflicts of interest in this work.

\section{References}

1. Arcaro A. Targeted therapies for small cell lung cancer: Where do we stand? Crit Rev Oncol Hemat. 2015;95(2):154-64.

2. van Meerbeeck JP, Fennell DA, De Ruysscher DK. Small-cell lung cancer. Lancet. 2011;378 (9804):1741-55.

3. Stupp R, Monnerat C, Turrisi AT, 3rd, Perry MC, Leyvraz S, Small cell lung cancer: state of the art and future perspectives. Lung Cancer. 2004;45(1):105-17.

4. De Ruysscher D, Botterweck A, Dirx M,
Pijls-Johannesma M, Wanders R, Hochstenbag M, et al. Eligibility for concurrent chemotherapy and radiotherapy of locally advanced lung cancer patients: a prospective, population-based study. Annals of Oncology, 2009;20(1):98-102.

5. Owonikoko TK, Ragin CC, Belani CP, Oton AB, Gooding WE, Taioli E, et al. Lung cancer in elderly patients: An analysis of the surveillance, epidemiology, and end results database. Journal of Clinical Oncology. 2007;25(35):5570-7.

6. Kato Y, Ferguson TB, Bennett DE, Burford TH. Oat cell carcinoma of the lung. A review of 138 cases. Cancer. 1969;23(3):517-24.

7. Quail DF, Joyce JA. Microenvironmental regulation of tumor progression and metastasis. Nature medicine. 2013;19(11):1423-37.

8. Chabner BA, Roberts TG. Timeline - Chemotherapy and the war on cancer. Nature Reviews Cancer. 2005;5(1):65-72.

9. Kang CH, Kang H, Shin HK, Shim BS, Kim SH, Choi $\mathrm{SH}$, et al. Experimental Studies on the Anti-angiogenesis and Anti-metastasis Effects of Ekong-san. Journal of Korean traditional oncology. 2006;11(1):41-54.

10. Lee SG, Ha JH. Antitumor and immunomodulatory effects of Ikongsan on murine melanoma-induced lung metastasis. Koren Journal of Oriental Medical Pathology. 1997;11(1):21-30.

11. Kuroiwa A, Liou S, Yan H, Eshita A, Naitoh S, Nagayama A. Effect of a traditional Japanese herbal medicine, hochu-ekki-to (Bu-Zhong-Yi-Qi Tang), on immunity in elderly persons. Int Immunopharmacol. 2004;4(2):317-24.

12. Nabeshima S, Murata M, Hamada M, Chong $Y$, Yamaji K, Hayashi J. Maturation of monocytederived dendritic cells by Hochu-ekki-to, a traditional Japanese herbal medicine. Int Immunopharmacol. 2004;4(1):37-45.

13. Li T, Tamada K, Abe K, Tada H, Onoe $\mathrm{Y}$, 
Tatsugami K, et al. The restoration of the antitumor $\mathrm{T}$ cell response from stress-induced suppression using a traditional Chinese herbal medicine Hochu-ekki-to (TJ-41:Bu-Zhong-Yi-Qi-Tang). Immunopharmacology. 1999;43(1):11-21.

14. Choi W, Jung H, Kim K, Lee S, Yoon S, Park $\mathrm{J}$, et al. Rhus verniciflua Stokes against Advanced Cancer: A Perspective from the Korean Integrative Cancer Center. Journal of biomedicine \& biotechnology. 2012;2012:874276.

15. Szasz A. Current status of oncothermia therapy for lung cancer. The Korean journal of thoracic and cardiovascular surgery. 2014;47(2):77-93.

16. Hegyi G, Szigeti GP, Szasz A. Hyperthermia versus Oncothermia: Cellular Effects in Complementary Cancer Therapy. Evidence-based complementary and alternative medicine : eCAM. 2013;2013:672873.

17. Melzer J, Iten F, Hostanska K, Saller R. Efficacy and Safety of Mistletoe Preparations (Viscum album) for Patients with Cancer Diseases A Systematic Review. Forschende Komplementarmedizin. 2009;16(4):217-26.

18. Elluru SR, Van Huyen JPD, Delignat S, Prost F, Heudes D, Kazatchkine MD, et al. Antiangiogenic Properties of Viscum Album Extracts Are Associated with Endothelial Cytotoxicity. Anticancer research. 2009;29(8):2945-50.

\section{ORCID}

Sanghun Lee: https://orcid.org/0000-0002-0573-9555 